to the ophthalmologist with pupillary defects, the cardiologist with orthostatic hypotension, the geriatrician because of failure of temperature regulation, the genitourinary surgeon with a neurogenic bladder. In some patients autonomic failure is part of a more generalized neurological atrophy which includes parkinsonian features, but in others it is associated with systemic diseases such as diabetes, alcoholism, amyloidosis, or carcinomatosis. Certain features of autonomic failure may also be produced by drugs.

It is, perhaps, strange that such an important syndrome should only have become widely recognized within the last decade, and that only now should the first definitive textbook on it appear. It is appropriate that it should have been prepared under the general editorship and with significant contributions from Sir Roger Bannister, for he and his colleagues have played a major role in the definition and investigation of this syndrome and its underlying pathophysiological and pharmacological abnormalities. In general this is a scholarly and up-to-date presentation of the information currently available on this diverse syndrome, with critical discussions of those aspects which are particular subjects of controversy. Autonomic pharmacology and synaptic transmission are subjects which are undergoing rapid and radical changes, and some parts of this book may well soon be out of date. Nevertheless it represents the best review of the subject now available and will undoubtedly become obligatory reading by all training in neurology, and an important source of reference for clinicians and basic scientists who are involved in diagnosis, treatment or research in this fascinating syndrome.

PaUl TURNer, St Bartholomew's Hospital, London ECIA 7BE.

Beta Blockade in the 1980s: Focus on Atenolol. Proceedings of an International Symposium, Monte Carlo 7-10th June, 1982 Drugs, Supplement 2, Vol. 25, March 1983

Edited by J. I. S. Robertson, N. M. KaPlan, A. D. S. CALDWEll and T. M. SPEIGHT. Pp. ix +346 , illustrated. Adis Press, New York, Tokyo, Mexico, Sydney, Auckland, Hong Kong, 1983, Price not given.

This volume is the proceedings from a large successful symposium on $\beta$-blocking drugs held in June 1982. There are five sections divided between, hypertension, pharmacodynamics and pharmacokinetics of $\beta$-blockers, angina and arrhythmias, hypertension of pregnancy, cardioselectivity, the central nervous system and myocardial infarction. The papers are succinct accounts of the state of the art in a rapidly changing field.

Two topics which are particularly well covered are those on comparison of $\beta$-blockers with calcium entry antagonists and a summary on the risks and benefits of $\beta$-blockers. The volume is well produced and the type is clear, if a little small in some figures. On a personal note, I missed the discussions which followed the papers and which helped the symposium to achieve a lively success.

R. M. Pearson,

St Bartholomew's Hospital, London ECIA 7BE

Diagnosis and Management of Endocrine Diseases. Diagnosis and Management Series.

By Anthony D. Toft, Ian W. Campbell and John Seth. Pp. vii + 414, illustrated. Blackwell Scientific Publications, Oxford, London, Edinburgh, Boston, Melbourne, 1981. £12.50.

This small volume provides an excellent guide to the clinical diagnosis and management of common endocrine problems, and should prove invaluable to the junior hospital doctor and MRCP candidate. The advice given reflects the wide experience of the authors and is a sound exposition of current British practice. Although the lack of any mention of paediatric endocrinology is usderstandable in a book of this size, there is a notable gap in the discussion of growth disorders as they present in an adult endocrine clinic. Diabetes and its complications account for over one-third of the text, and while this may reflect the prevalence of diabetes mellitus in the general population, it must be asked whether it is right for a textbook of general endocrinology to have 14 pages on diabetic autonomic neuropathy, but not a single word on congenital adrenal hyperplasia.

Despite these criticisms, the book fulfills its purpose very well. The text is clearly written in short paragraphs with frequent subheadings, and is printed to a high standard. I would recommend it.

Peter J. A. Moult,

Whittington Hospital,

London N19 5NF.

Diagnosis and Management of Respiratory Diseases, Diagnosis and Management Series

By Graham K. Crompton. Pp. ix +269 , illustrated. Blackwell Scientific Publications, Oxford, 1980. $£ 9.80$.

Some 5 years ago the publishers initiated a series of short texts on specialist subjects by younger physicians. The first of these was written by Dr Graham Crompton, Consultant Physician on the Respiratory Diseases Unit of the Northern General Hospital, Edinburgh and Honorary Senior Lecturer in the Department of Respiratory Diseases, Edinburgh University. The text is aimed at a wide readership including medical students, MRCP candidates, general practitioners and 'the clinician faced with a problem'.

The introductory chapter is devoted to clinical findings and investigative procedures. These include chest radiology, simple lung function tests and bronchoscopy. The remaining 19 chapters deal with individual diseases (e.g. chronic bronchitis, emphysema, bronchiectasis) or groups of diseases (e.g. occupational lung diseases, abnormalities of chest wall and diaphragm). The layout of these chapters consists of general considerations, complications, clinical findings, investigations, differential diagnosis and treatment. Useful tables and lists and 20 simple diagrams are included. No references or reference lists are provided, but a short list of recommended further reading is appended at the end of the book.

It was a pleasure to read this book as the style is clear with brief sentences and chapters. There would be a case for discussing complications after clinical findings as these often result from further progression of the disease process which has caused the symptoms and physical signs. A novel feature is the 'summary-special points of emphasis' at the end of each chapter. This highlights the important points covered. Curiously, in the chapter on tuberculosis, the importance of using two or more drugs in treatment was not included in this list. The description of radiological changes is sometimes vague (e.g. cystic fibrosis) and might be helped by line diagrams of chest radiographs.

Because of the request for a clear and concise text from one author, the style had to be dogmatic without discussion of controversial issues. Thus the author sometimes describes techniques and personal views that are not universally accepted. For example, not all respiratory physicians perform bronchography under general anaesthesia or at the same time as bronchoscopy and only a minority employ radiotherapy to peripheral lung nodules to assess whether or not they are malignant.

The first edition was published in 1980; thus some aspects are naturally out of date. There is no mention of the diagnostic value of bronchopulmonary lavage or the measurement of circulating lymphocyte subpopulations and serum angiotensin converting enzyme. Published and personal experience of tuberculosis cases relapsing after treatment nowadays has shown that the organisms are nearly always still sensitive to modern first line drugs. Mustine has been largely superseded by modern anticancer combinations in the systemic treatment of bronchial carcinoma and by bleomycin tetracycline and $C$ parvum in the management of malignant pleural effusions. Adjuvant immunotherapy has proved disappointing in patients undergoing resection of bronchial carcinoma and disodium cromoglycate can now be administered by pressurized aerosol inhaler.

Virtually all respiratory disorders are covered, although it was a surprise to find no mention of acute bronchitis. Pleural mesothe- 
lioma is now a major problem in ship building areas and merits more detailed description. Occasionally, an extra sentence would have helped the third year medical student, for example a description of erythema nodosum and the technique of bronchography.

At this very reasonable price, the book is a good buy for undergraduate and postgraduate students. It fits easily into a white coat pocket and is thus a handy reference source for any doctor working on a respiratory medicine unit. There should be a copy in the hospital library and on the bookshelves of general medical and respiratory medical wards.

B. H. R. STACK, Western Infirmary, Glasgow G11 6NT.

The Health Care Manual: a Family Guide to Self-Care and Home Medicines

Edited by JOHN FRY and GORDON FRYERS with contributions from Eric Gambrill, Alistair Moulds, Gilliam Strube and Ken Young. Pp. vii + 320. MTP Press, Lancaster, Boston, The Hague, 1983. £3.95.

Demand for medical care is infinite but the time available to meet it is not. Time spent by general practitioners dealing with minor selflimiting conditions like coughs and colds is denied to preventive activities such as finding and treating hypertension, which threatens the life expectancy of $10 \%$ of the population, and patient education about avoiding disease. Less time should be spent on minor illnesses and much more on preventing major disease.

Its first section is about keeping healthy and is in general sound particularly on sleep, sex and stress. But there are infelicities. Hospital doctors do not, except in rare cases, treat hypertension, general practitioners do. They may be family doctors but are not in this country called family physicians. Advice not to smoke more than 10 cigarettes daily is bad because half-hearted, and not to drink at all is misleading. A pint or two of beer or several glasses of wine per day, according to no less authority than Sir Richard Doll, reduces the risk of death from cardiovascular disease.

The second section, about common problems, explains how almost everything from animal bites to undescended testis can be treated by self-care. The third discusses diseases which have been diagnosed by doctors in words which can be comprehended by laymen.

This book is clearly written by family doctors and is to be recommended highly to patients who prefer autonomy to dependence.

ANDREW SMITH, Whickham Health Centre, Newcastle upon Tyne.

\section{Lead versus health: sources and effects of low level lead exposure}

Edited by Michael Rutter and Robin Russell Jones. Pp. xiv +379 , illustrated. John Wiley \& Sons, Chichester, New York, Brisbane, Toronto, Singapore, 1983. $£ 18.50$.

This book is a collection of papers on the absorption, metabolism and biological and psychological effects of lead.

Much of the evidence concerning the effect of lead upon health is not clear-cut and some of it is conflicting, but in the crucial area of its effect upon intelligence, the overall conclusion seems to be that lead does effect I.Q. slightly - of the order of 3-5 I.Q. points-and while this finding is, strictly speaking not statistically significant it is important because it is consistent over several studies, and on this basis as well as other evidence is likely to implicate lead as the max factor in accounting for this difference.

However, blood levels in the U.S. have fallen by $37 \%(5.4 \mathrm{~g} / \mathrm{df})$ from 1976-1980, and the most likely explanation for this is the reduction in petrol lead during this period (New England Journal off Medicine, June 9th 1983), and so it seems that this is an effective manoeuvre in reducing blood lead. The decision has been made 8 lower the lead content of petrol in the U.K. from $0.4 \mathrm{~g} / 1$ to $0.15 \mathrm{~g}$. by 1985 , and it is likely that it will be phased out altogether by 1990 However, leaded petrol will continue to be on sale for at least years after this date. The small effect of lead upon I.Q. and the slow phasing out of petrol lead and the very large number of variables which contribute to intelligence will make it virtually impossible to make accurate assessments of any change.

Although the effects of lead reduction are likely to be smalt because intelligence and behaviour are so important it seems the one must take advantage of any opportunity to improve these factors.

This book gives a good overall view of this complex subject and. the discussions after each paper and the overall summaries are of particular value.

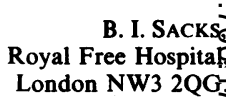

\section{Short Cases for the MRCP}

By K. GuPTA. Pp. xii + 106. Chapman and Hall, London, New York, 1983. £4.75.

This book has the limited but laudable objective of trying to help the M.R.C.P. candidate prepare for the short case section of the clinical examination. This, now extended, part of the clinical is regardey âs the most discriminating and taxing hurdle. It is also the hardeston $\vec{B}$ for which to give written advice. There can never be a substitute feg examining patients at the bedside, against the clock, in the presence of an interrogator who will not only question the candidate on this findings and their interpretation, but will also assess his clinic technique.

The author sets about his task by devising a comprehensive list $\overline{\bar{\sigma}}$ 100 clinical situations the candidate might face. This is unexce tional and will not add much to the candidate's anticipation or fearg though a knowledge of Laurence-Moon-Biedl syndrome or acanthosis nigricans will not, one hopes, greatly impress the examiner. $\overline{\widehat{d}}$ page is devoted to each condition attempting to highlight thro cardinal signs and associated features in other parts of the bodgy relating to it. The crucial and difficult part is the attempt anticipate the questions the examiner may then proceed to ask and this is largely tackled by giving lists of differential diagnoses.

Apart from minor typographical errors and some illogicalities the sequence of cases (83. Carpal tunnel syndrome might, more sensibly come next to 87 . Median nerve palsy rather than separated by Absent radial pulse, Claw hands and Wrist drop) thes notes are accurate.

Ultimately the success and value of the book will depend on the predictability of different examiners to ask the same questions aboa the same cases. One hopes that their originality may be greater than implied.

ERIC BECK? Whittington Hospita London N19 5NFO 